\title{
Target Control Infusion (TCl) Computer-assisted Pump and Bispectral Index (BIS) Monitoring Sedation System in Elderly Patients During Endoscopic Retrograde Cholangiopancreateography (ERCP)
}

\author{
Kai $\mathrm{LI}^{1}$, Bin $\mathrm{ZHANG}^{2}$, Ying $\mathrm{ZHANG}^{2,}{ }^{*}$, Fang $\mathrm{WANG}^{2}$ and Chun-mei \\ $\mathrm{CHU}^{2}$ \\ ${ }^{1}$ Anesthesiology department, \\ ${ }^{2}$ Endoscopic center, China-Japan union hospital of Jilin university, \\ $126^{\text {th }}$ Xian-Tai avenue , Changchun city, Jilin province, P.R.China,130021 \\ 124777681@qq.com 13596195176 \\ *corresponding author:
}

Keywords: Computer-assisted Pump, Bispectral Index (BIS), Target Control Infusion (TCI), Endoscopic Retrograde Cholangiopancreateography (ERCP), Propofol.

\begin{abstract}
Objectives: The aim of this study was to investigate the safety and efficacy of propofol sedation with a target-controlled infusion (TCI) computer-assisted pump and bispectral index (BIS) monitoring in elderly patients during endoscopic retrograde cholangiopancreateography (ERCP). Methods: Included were 150 consecutive EPCP procedures elderly patients under propofol sedation with a TCI system. Patients were divided into 3 groups: group A, age 50-70 years $(n=50)$; group $B$, age 71-80 years $(\mathrm{n}=50)$; group $\mathrm{C}$, age $>80$ years $(\mathrm{n}=50)$. We compared the propofol dose and adverse events (hypotension and hypoxemia) during ERCP. Results: Older patients required a lower target concentration of propofol with higher age period: Median target concentration are respectively $2.6 \mu \mathrm{g} / \mathrm{mL}, 2.1 \mu \mathrm{g} / \mathrm{mL}$ and $1.6 \mu \mathrm{g} / \mathrm{mL}$ in the three groups. Hypotension tended to occur in the younger group, and hypoxemia occurred at a significantly higher rate in the older groups, although the number of cases was small. Low preoperative systolic blood pressure $(<80 \mathrm{~mm} \mathrm{Hg})$ was associated with hypotension and abnormal pulmonary function was associated with hypoxemia in groups B and C. Conclusions: Elderly patients required lower doses of propofol with TCI/BIS system than younger patients. Attention to hypoxemia is necessary in elderly patients, particularly patients with abnormal pulmonary function.
\end{abstract}

\section{Introduction}

Endoscopic retrograde cholangiopancreatography (ERCP) is commonly used in the management of many pancreatobiliary disorders, such as common bile duct stones, pancreatic cancer. In comparison with upper gastrointestinal endoscopic procedures, ERCP is a longer and more complex procedure planned in prone position, with a substantially higher complication rate [1].Sedation in ERCP may be responsible for some postoperative adverse events especially for elderly patients [2].The most commonly complications in ERCP with sedation including cardiopulmonary events such as hypoxemia, hypoventilation, airway obstruction, apnea, arrythmia, hypotension, and vasovagal episodes [3]. 
It can be hypothesized that elderly patients require lower doses of sedation to achieve similar pharmacological effects compared with younger patients. A target-controlled infulion (TCI) system, which is the computer-assisted pump enables automatic control of the dose of sedative drugs by a infusion algorithm of pharmacokinetics for calculating the effect-site concentration [4] However, the pharmacokinetic model in the TCI pump may not be optimal when considering the age and concomitant disease in individual patients [5]. Bispectral index (BIS) monitoring is an electroencephalography based method that quantifies the depth of anesthesia by analyzing the electroencephalogram and uses a complex algorithm to generate an index score, providing an objective measurement of the level of consciousness in sedated patients [6]. Recently, the utility of the combination of a TCI pump and BIS monitoring system (TCI/BIS system) for endoscopic treatment was reported [7].

However, there is limited information on the outcomes of sedation used in elderly patients . This study aimed to evaluate the safety and efficacy of propofol sedation with TCI/BIS system for elderly patients during ERCP.

\section{Methods}

\section{Patients and Study Design}

A total of 150 consecutive ERCP procedures for early patients were performed at the endoscope center of China-Japan union hospital of Jilin university by using propofol sedation with a TCI/BIS system between October 2013 and September 2014 were included in this study. Patients were divided into 3 groups according to ages: group A, age 50-70 years $(n=50)$; group $B$, age71-80 years $(n=50)$; group $C$, age $>80$ years $(n=850)$. After recording gender, body mass index, results of lung function testing, preoperative SBP, preoperative peripheral capillary oxygen saturation. Infusion of propofol was continued until the end of the procedure.

\section{Medication and Monitoring}

Pharyngeal anesthesia was performed by using an $2 \%$ topical lidocaine spray before intravenous infusion of the sedative drugs. Propofol was administered intravenously by using the Diprifusor system which is a TCI system using the pharmacokinetic kinetic parameter set according to the Marsh model. The initial setting of the target blood concentration of propofol (1\% Diprivan Injection-kit; AstraZeneca) was set at $2.0 \mu \mathrm{g} / \mathrm{mL}$ for the nonelderly patients $<70$ years old). The initial setting for the elderly patients (>70 years old) was $1.0 \mu \mathrm{g} / \mathrm{mL}$, which was chosen for moderate sedation [7]. The blood concentration of propofol at each time point was calculated automatically and shown on the monitor of the TCI pump. For the objective measurement of the level of consciousness in sedated patients, the A2000 BIS monitor (Aspect Medical Systems, Newton, Mass) was used. The BIS score was kept between 50 and 80 . In the procedure period, if the BIS score went beyond the range of 50-80, the target blood concentration was changed by $0.2 \mu \mathrm{g} / \mathrm{mL}$ each time. An additional bolus of 1 to $2 \mathrm{~mL}$ of propofol was given if the patient's movements were frequent. When adverse event (SBP $<80 \mathrm{mmHg}$ or Spo $2<90 \%$ ) occurred, the target blood concentration of propofol was reduced by $0.2 \mu \mathrm{g} / \mathrm{mL}$ with an immediate increase in the intravenous drip or oxygen dose. $1 \mu \mathrm{g} / \mathrm{kg}$ fentanyl was infusioned as an analgesic agent. All patients received supplemental oxygen $(2 \mathrm{~L} / \mathrm{min})$ by nasal cannula during sedation and were kept in the lateral decubitus position. If hypoxemia occurred during the sedation, chin lift on the patient and increased the oxygen dose was performed. 
Pulse rate, blood pressure, electrocardiogram, and Spo2 were monitored continuously during the procedure. Blood pressure was recorded every 5 minutes. All adverse events including hypoxemia (Spo2<90\%) and hypotension $(\mathrm{SBP}<80 \mathrm{mmHg}$ ), and the total propofol dose were recorded during the ERCP.

\section{Statistical Analysis}

Continuous variables are presented as the median and range or interquartile range (IQR). Comparison of continuous variables was performed by the Mann-Whitney U test, and comparison of dichotomous variables was made by using the Fisher exact test and logistic regression. To extract significant factors for each of major adverse events concerning propofol sedation(hypotension or hypoxemia), multivariate analyses were done by using logistic regression analysis. The significance level was set at $\mathrm{P}<0.05$. The resultant data were evaluated by using JMP software version 11 (SAS Institute, Cary, $\mathrm{NC})$

\section{Results}

There were no statistically differences between groups in gender, body mass index, procedure time (see Table 1).

The older groups needed lower median target concentration, respectively $2.6 \mu \mathrm{g} / \mathrm{mL}$, $2.1 \mu \mathrm{g} / \mathrm{mL}$ and $1.6 \mu \mathrm{g} / \mathrm{mL}$ in the three groups. The total infusion doses of propofol was lower in older groups (see Table 1)

In addition, there were no statistically significant differences among groups in the percentages of Spo2. Hypotension (as defined by $\mathrm{SBP}<80 \mathrm{~mm} \mathrm{Hg}$ ) tended to occur more often in the younger groups, but the difference was not significant (group A: $35.6 \%$; group B:28.5\%; group C: $23.3 \%, \mathrm{P}=0.072$ ). Hypoxemia occurred significantly more often in the older group, but the prevalence was low (group A: 0\%; group B: $2.6 \%$; group $\mathrm{C}: 5.5 \%, \mathrm{P}=0.001$ ). All patients recovered from hypoxemia within 30 seconds. Only 4 patients needed vasopressor drugs to recover from hypotension, and no patient needed mask assisstant breath or intubation. In addition, all patients were stable under good sedation. (see Table 1).

Table 1 characteristics of procedures and adverse events

\begin{tabular}{|c|c|c|c|c|}
\hline characteristics & $\begin{array}{c}\text { Group A } \\
(50-70 y e a r)\end{array}$ & $\begin{array}{c}\text { Group B } \\
(71-80 \text { year })\end{array}$ & $\begin{array}{c}\text { Group C } \\
(>80 y e a r)\end{array}$ & P value \\
\hline BMI $\left(\mathrm{kg} / \mathrm{m}^{2}\right)$ & $22.4(20.5-24.4)$ & $22.8(21.0-25.0)$ & $22.5(20.7-24.8)$ & 0.076 \\
\hline procedure time $(\mathrm{min})$ & $43.5(34.8-72.3)$ & $48.0(38.0-88.2)$ & $46.0(37.6-90.4)$ & 0.093 \\
\hline $\begin{array}{c}\text { Minimum concentration of } \\
\text { propofol }(\mu \mathrm{g} / \mathrm{mL})\end{array}$ & $1.8(1.4-2.0)$ & $1.6(1.2-1.8)$ & $1.3(1.0-1.7)$ & $<0.003$ \\
\hline $\begin{array}{c}\text { Maximum concentration of } \\
\text { propofol }(\mu \mathrm{g} / \mathrm{mL})\end{array}$ & $3.3(2.6-3.8)$ & $2.9(2.4-3.6)$ & $2.6(2.0-3.2)$ & $<0.001$ \\
\hline $\begin{array}{c}\text { Average concentration of } \\
\text { propofol }(\mu \mathrm{g} / \mathrm{mL})\end{array}$ & $2.6(2.2-3.2)$ & $2.1(1.7-2.8)$ & $1.6(1.5-2.5)$ & $<0.001$ \\
\hline $\begin{array}{c}\text { Total infusion dose of } \\
\text { propofol }(\mathrm{mL})\end{array}$ & $43(30-62)$ & $35(23-48)$ & $30(18-40)$ & $<0.001$ \\
\hline $\begin{array}{c}\text { Hypotention incidence } \\
(\text { SBP }<80 \mathrm{mmHg})(\%)\end{array}$ & 35.6 & 28.5 & 23.3 & 0.072 \\
\hline $\begin{array}{c}\text { Hypoxemia incidence } \\
(\text { Spo2<90\%)(\%) }\end{array}$ & 0 & 2.6 & 5.5 & 0.01 \\
\hline
\end{tabular}




\section{Discussion}

Deep sedation in general endoscopic treatment for older patients are limited [7, 8]. This report evaluated the efficacy of the TCI/BIS system for propofol sedation during ERCP in different age period elder patients. In the study, there was an inverse correlation between age and target concentration of propofol. The patients was older, the lower concentration and dose of propofol with the TCI/BIS system. With regard to adverse events, the proportion of those with hypotension was highest in group A, which was the youngest elder group, whereas the rate of hypoxemia was significantly higher in the older groups (group B and C), although the number of patients with this adverse event was small. The possible cause of hypoxemia in group $\mathrm{C}$ was that those patients had more frequent episodes of hypoxemia during natural sleep than those in group A. Hypotension mostly occurred in the maintenance period, whereas hypoxemia occurred in both the maintenance and recovery periods. Propofol sedation in the elderly patients during ERCP with the TCI/BIS system was as safe as in the younger patient group.

Propofol is a non barbiturate sedative hypnotic. It has a favorable pharmacokinetic profile as the lipid solubility confers a quick onset and short recovery time. The safety of propofol sedation for endoscopy in elderly patients was also reported [9] . Although it is extremely effective and potent, propofol is limited by a relatively high incidence of dose-dependent hypotension and respiratory depression [10] . Once cardiorespiratory inhibition has occurred, it is necessary to provide cardiorespiratory support until propofol is metabolized because there are no antagonists available. To avoid excessive infusion of propofol, we used the BIS monitoring system, which makes objective evaluation of the depth of sedation possible. BIS evaluates different parts of the electroencephalogram at various stages. Because the BIS value is generally set at 45 to 65 during surgical procedures withgeneral anesthesia, we set BIS values at 50 to 80 during ERCP. Several studies of BIS monitoring sedation during endoscopic procedures showed its effectiveness [6]. In the study, there was an inverse correlation between age and the target concentration of propofol to maintain BIS values below 80 . As a result, it was possible to maintain stable sedation with a lower amount of propofol for elderly patients than younger ones with a TCI/BIS system. It was shown that elderly patients require a lower amount of propofol to reach similar levels of sedation than younger [11] .This result suggests that strict control of infusion by the TCI pump adjusted by titralion of the individual sedation depth by BIS monitoring could decrease the dose of propofol in elderly patients.

In the study, hypotension was frequently in the maintenance period. In particular, low preoperative SBP was associated with hypotension independent of the age group. Because of the short-acting characteristics of propofol, almost all patients recovered immediately with decreases in the dose of propofol without using a vasopressor drug. Contrary to our expectation, hypotension occurred at a higher rate in the younger patient group. The result might be explained by the more rapid rate of increase in propofol concentrations [12] .The BIS monitoring system was recommended to avoid hypotension in the elderly [13] .It is believed that stability of the sedation state in the older patient groups through the BIS/TCI system and the higher preoperative SBP in the aged groups.

This study has some limitations. Firstly, the initial target concentrations of propofol differed among three group, it might resulted in an increased propofol dose and hypotension in group A. However, the BIS maintenance target score was the same among the groups, and the target doses were adjusted to the prepdicted concentration at 
the time when the BIS score decreased to less than 80. Furthermore, the synergic action of opioid drugs might have resulted in the occurrence of adverse events. We used fentanyl in our study, the synergic action of fentanyl might explain the occurrence of this adverse event.

\section{References}

[1]. L Fisher, R Jain, SO Ikenberry, et al. Complications of ERCP. Gastrointestinal endoscopy. 75( 2012):467-473

[2]. K Khan, O Steven. Bo, Shen Stewarl L, et al. Sedation and anesthesia in GI endoscopy. Gastrointestinal endoscopy.68(2008):815-826.

[3]. A Beeton, ERCP: sedation or anaesthesia? South Afr J Anaesth Analg. 17(2011):124-125.

[4]. RM Tackley, GT lewis ,C Prys-Robert, et al.Computer controlled infusion of propofol .Br J Anaesth.62(1989):46-53.

[5]. JE Mandel, E Sarraf. The variability of response to propofol is reduced when a clinical observation is incorporated in the control: a simulation study.Anesth Analg.114(2012):1221-1229.

[6]. SC Chen, DK Rex. An initial investigation of bispectral monitoring as an adjunct to nurse-administered propofol sedation for colonoscopy. Am Gastroenterol. 99(2004):1081-1086.

[7]. A Imagawa, H Hata, M Nakatsu, et al. A target-controlled infusion system with bispectral index monitoring of propofol sedation during endoscopic submucosal dissection. Endosc Int Open.3(2015):E2-6.

[8]. T Gotoda, C Kusano, M Nonaka, et al. Non-anesthesiologist administrated propofol (NAAP) during endoscopic submucosal dissection for elderly patients with early gastric cancer. Gastric Cancer .17(2014): 686-691.

[9]. A Kerker, C Hardt, HE Schlief, et al. Combined sedation with midazolam/propofol for gastrointestinal endoscopy in elderly patients. BMC Gastroenterol .10(2010):11.

[10]. J Fechner, H Ihmen, D Hatterscherd, et al. Comparative pharmacokinetics and pharmacodynamic of the new propofol prodrug GPI 15715 and propofol emulsion.Anesthesiology.101(2004):626-639.

[11]. JF Martinez, JR Aparicio, L Company, et al. Safety of continuous propofol sedation for endoscopic procedures in elderly patients. Rev Esp Enferm Dig.103(2011):76-82.

[12]. GE Van Poucke, LJ Bravo, SL Shafer. Target controlled infusions: targeting the effect site while limiting peak plasma concentration. IEEE Trans Biomed Eng .51(2004):1869-1875.

[13]. T Ishiyama, T Oguchi, T Kumazawa. Baroreflex sensitivity and hemodynamic changes in elderly and young patients during propofol anesthesia. J Anesth 17(2003):65-67. 